\title{
The Effect of Hydrogen on the Parameters of Plastic Deformation Localization in Low Carbon Steel
}

\author{
Aleksey G. Lunev ${ }^{1,2, a)}$, Mikhail V. Nadezhkin, 2, b), Galina V. Shlyakhova ${ }^{1,3, c)}$, \\ Svetlana A. Barannikova ${ }^{1,4,5, \mathrm{~d})}$, and Lev B. Zuev ${ }^{1,4, \mathrm{e})}$ \\ ${ }^{1}$ Institute of Strength Physics and Materials Science SB RAS, Tomsk, 634055, Russia \\ ${ }^{2}$ National Research Tomsk Polytechnic University, Tomsk, 634050, Russia \\ ${ }^{3}$ Seversk State Technological Institute (National Research Nuclear University MEPhI), Seversk, 636036, Russia \\ ${ }^{4}$ National Research Tomsk State University, Tomsk, 634050, Russia \\ ${ }^{5}$ Tomsk State University of Architecture and Building, Tomsk, 634003, Russia \\ a) Corresponding author: agl@ispms.tsc.ru \\ b) nadjozhkin@ispms.tsc.ru \\ c)shgv@ispms.tsc.ru \\ d)bsa@ispms.tsc.ru \\ e) $1 \mathrm{bz} @$ ispms.tsc.ru
}

\begin{abstract}
In the present study, the effect of interstitial hydrogen atoms on the mechanical properties and plastic strain localization patterns in tensile tested polycrystals of low-carbon steel $\mathrm{Fe}-0.07 \% \mathrm{C}$ has been studied using double exposure speckle photography technique. The main parameters of plastic flow localization at various stages of deformation hardening have been determined in polycrystals of steel electrolytically saturated with hydrogen in a three-electrode electrochemical cell at a controlled constant cathode potential. Also, the effect of hydrogen on changing of microstructure by using optical microscopy has been demonstrated.
\end{abstract}

Keywords: hydrogen, speckle photography, strain localization, plasticity, wavelength

\section{INTRODUCTION}

Previously, we presented experimental data [1-5] according to which the plastic strain development in solids exhibited localized character over the entire process. This phenomenon is especially clearly manifested on a macroscopic scale, where the patterns of strain localization are related to the deformation hardening operative on the corresponding stages of straining. In this case, the observed patterns acquire the form of autowaves of various types, and there is a unique relationship between the autowave type and the law of strain hardening at this stage of plastic flow in single crystals and polycrystals.

The presence of hydrogen $(\mathrm{H})$ in solid solution in metals and alloys is attributed mainly to the small diameter of this element and its capacity to diffuse with certain ease in solid state substances. Different factors contribute to elevate or diminish the solubilization and/or diffusion of $\mathrm{H}$ in steels. The main ones are temperature, alloy composition, crystalline structure and substructure. Nevertheless, the presence of $\mathrm{H}$ in metals and specifically in steels is not desired in most of the cases, since $\mathrm{H}$ alters considerably the mechanical-metallurgic properties of these materials with the possibility of a fracture $[6,7]$. The most typical damage caused by $\mathrm{H}$ in steel is embitterment. Embitterment due to $\mathrm{H}$ involves a vast loss of mechanical properties with the following characteristics such as, for example, decrease of ductility and fracture tension with the increase in $\mathrm{H}$ concentration.

The main goal of this investigation was to elucidate the effect of dissolved hydrogen on macroscopic plastic flow localization patterns in tensile strained low-carbon steel polycrystals.

International Conference on Physical Mesomechanics of Multilevel Systems 2014

AIP Conf. Proc. 1623, 371-374 (2014); doi: 10.1063/1.4898959

(C) 2014 AIP Publishing LLC 978-0-7354-1260-6/ $\$ 30.00$ 


\section{MATERIALS AND EXPERIMENTAL METHODS}

Complex investigations of the nature of plastic deformation inhomogeneity performed on samples of low-carbon steel [chemical composition (in wt \%): C 0.07, Mn 0.25, Si 0.05, S 0.05, P 0.04, Cr 0.3, Ni 0.3 and Cu 0.3]: after hot rolling (condition 1), and after laboratory-performed electrolytic hydrogen saturation of the samples after hot rolling (condition 2). The initial average grain size in the cross section of a sample was $\sim 24 \pm 13 \mu \mathrm{m}$ and, longitudinally, $\sim 20 \pm 11 \mu \mathrm{m}$. Samples with the working part dimensions of $50 \times 10 \times 2 \mathrm{~mm}$ have been tensiled with an LFM-125 testing machine, at $300 \mathrm{~K}$ at the rate of $0.2 \mathrm{~mm} / \mathrm{min}$. The method of double-exposure speckle photography (DESP) was used for investigating macrolocalization plastic flow [1]. Hydrogen-charging of the samples was carried out within a three-electrode electrochemical cell at the temperature of $323 \mathrm{~K}$ over 24 hours under exposure to a continuously controlled cathode [8], with $-600 \mathrm{mV}$ potential relative to a silver chloride electrode in 1 Normal sulfuric acid solution supplemented with $20 \mathrm{mg} / \mathrm{l}$ of thiourea. Current-voltage curves were recorded using an IPCCompact potentiostat. Before the mechanical testing, the hydrogenated samples were stored in liquid nitrogen. The absolute concentration of hydrogen in the samples was determined with a 602 RHEN analyzer, via by melting them in an inert atmosphere. The method of atomic emission spectrometry was used for stratified analysis of the hydrogen distribution throughout the sample thickness by a glow-discharge spectrometer (Profiler-2). Studies of the microstructure were conducted using optical microscopy (Neophot-21).

\section{EXPERIMENTAL RESULTS}

We have studied the evolution of patterns of the plastic flow macrolocalization in low-carbon steel polycrystals in the initial state and upon the saturation of the electrolytes with hydrogen.

The stress-strain $(\sigma-\varepsilon)$ curve of plastic flow measured under tension for low-carbon steel polycrystals exhibit a tooth and a flow-through and is followed by the stages of parabolic (Taylor's) hardening with a power index of $n=$ $1 / 2$ and a prefracture with $n<1 / 2$ (Fig. 1). The hydrogenation of low-carbon steel polycrystals during 8, 14, 20, 24 hours led to a decrease in the yield and strength stresses, and the relative elongation after breaking.

The measurements of local strain distributions using the DESP method showed that the strain is macroscopically localized at all stages of plastic flow in low-carbon steel polycrystals. An analysis of these patterns revealed that, in the initial (hydrogen-free) state of polycrystals, the tensile plastic strain at the stage of yield plateau in the deforming material travels a solitary front of plastic deformation at a constant rate $V=8.8 \cdot 10^{-5} \mathrm{~m} / \mathrm{s}$, which separated the strained and unstrained parts of the sample (Fig. 2(a)). At the stage of parabolic deformation hardening, the localized zones exhibited a characteristic spacing of $\lambda=7.0 \pm 1 \mathrm{~mm}$.

An analysis of the distributions of local strain $\varepsilon_{x x}$ in tensile tested low-carbon steel polycrystals saturated hydrogen over 24 hours showed that, in this case at the flow-through in the material, tree deformation fronts emerge that move in the opposite directions. The average fronts' motion rates are $1.15 \cdot 10^{-4} \mathrm{~m} / \mathrm{s}$ (Fig. 2(b)). The point at which the fronts meet marks the end of the yield plateau. At the stage of parabolic deformation hardening, the localized zones exhibited a characteristic spacing of $\lambda=5.0 \pm 1 \mathrm{~mm}$ and the system of strain localization zones became stationary.

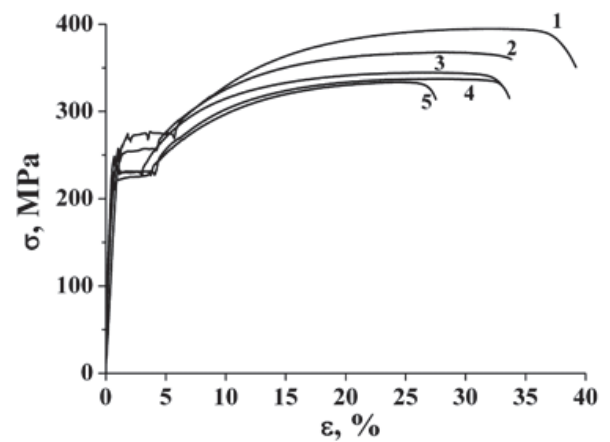

FIGURE 1. Low-carbon steel $(\mathrm{Fe}-0.07 \% \mathrm{C})$ loading curves for the temperatures within $300 \mathrm{~K}: 1$ - samples in the initial condition (without hydrogen), 2, 3, 4, 5- samples hydrogenated in a three-electrode cell

at a constant potential over $8,14,20,24$ hours 


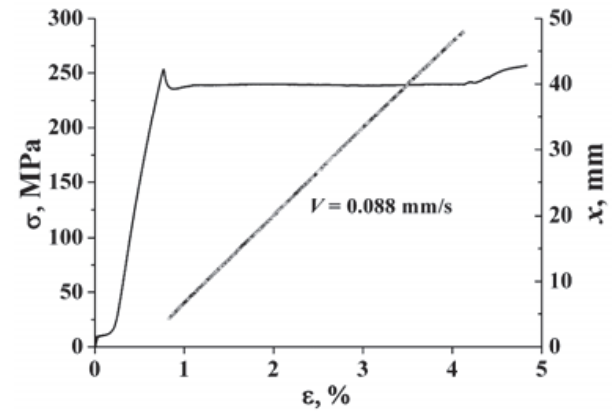

(a)

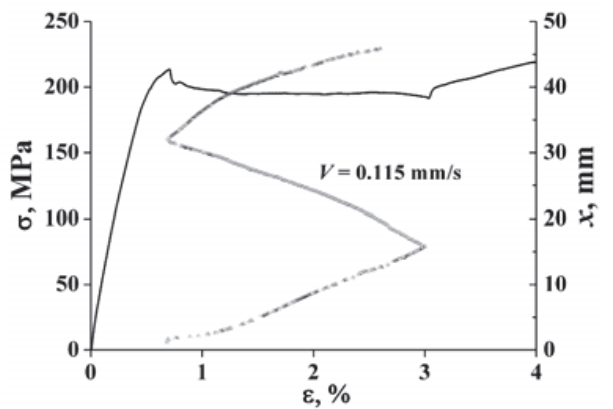

(b)

FIGURE 2. Localization patterns of the plastic deformation of steel samples on the yield plateau: (a) initial condition (without hydrogen), (b) hydrogenated condition over $24 \mathrm{~h}$ in three-electrode cell using constant potential

The structure of localization focus in condition 2 is difficult in contrast to condition 1 . In this case, the highamplitude peaks of local deformations divided by the aggregate of low-amplitude peaks were revealed [9]. At the prefracture stage, the immobile foci of plastic strain localization started moving consistently with a tendency to merge into a high-amplitude focus of localized straining, where a neck-like narrowing of the sample cross section was formed.

It was found that hydrogen enhances the deformation localization and alters the quantitative parameters of the plastic strain localization pictures: the length and autowaves velocity of plastic strain localization.

The metallographic examination of samples was carried out with an optical microscope. The microstructural investigation of $\mathrm{Fe}-0.07 \% \mathrm{C}$ steel in the initial condition showed that ferrite is the main structural component, and there is also perlite (Fig. 3(a)) that is typical for low-carbon steels after hot rolling. The structure of steel after electrolytic hydrogenation is shown in the Fig. 3(b, c). The mechanism of the hydrogen effect on structure and properties of steel leads to changes associated with hardening and the formation of micropores [10].

\section{CONCLUSION}

Thus, we have elucidated the effect of hydrogen on the macroscopic patterns of plastic strain localization in tensile tested polycrystals of low-carbon steel $(\mathrm{Fe}-0.07 \% \mathrm{C})$. It is established that hydrogenation enhances the localization of straining leading to significant changes in the characteristics distances between local straining zones, and this can be the result of interdislocation interactions and the generation of defects. Hydrogen reacts with cementite to form hydrocarbon compounds in the phase boundary [10], and the pressure of its compounds reaches critical values which may lead to breakage. Thus, during subsequent deformation of prehydrogenated steel, the area with high level defects (which have been identified in the grain boundaries) will subsequently be subject to microcracks' sites formation. The change in the microstructure of steel affects the stress-strain curves and also affects plastic strain localization patterns.

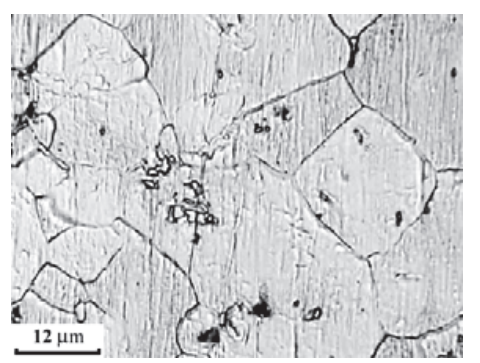

(a)

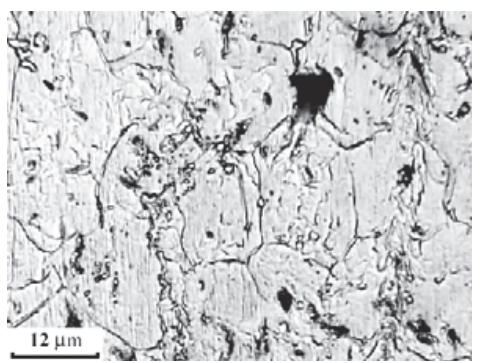

(b)

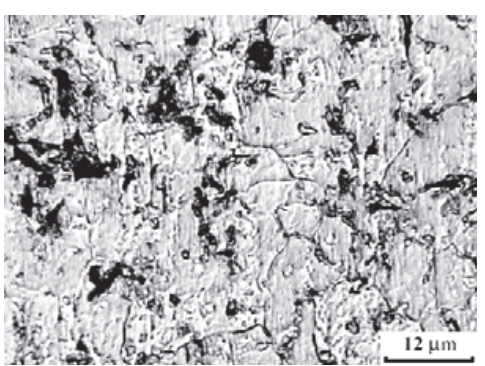

(c)

FIGURE 3. Structure of $\mathrm{Fe}-0.07 \% \mathrm{C}$ steel (optical microscopy): (a) initial condition, (b) hydrogenated condition over $16 \mathrm{~h}$, (c) hydrogenated condition over $24 \mathrm{~h}$ 
The comparison of the data for the two conditions (the initial condition and one after hydrogenation) of $\mathrm{Fe}-$ $0.07 \% \mathrm{C}$ steel showed that the localized plasticity sites have been formed and evolved throughout the plastic flow process during tensile testing. Hydrogen enhances localization and changes the quantitative parameters of macroscopic plastic strain localization: the length and the velocity of autowaves plastic strain localization [9, 11]. The mechanism of hydrogen-stimulated plastic strain localization is still under discussion [6].

\section{ACKNOWLEDGMENT}

The work was performed in the frame of the Program of Fundamental Research of State Academies of Sciences for 2013-2020.

\section{REFERENCES}

1. L. B. Zuev, V. I. Danilov, S. A. Barannikova, and V. V. Gorbatenko, Phys. Wav. Phen. 17, 1 (2009).

2. S. A. Barannikova, Tech. Phys. Lett. 30, 338 (2004).

3. S. A. Barannikova, Tech. Phys. 45, 1368 (2000).

4. L. B. Zuev and S. A. Barannikova, Natur. Sci. 2, 476 (2010).

5. $\quad$ L. B. Zuev and S. A. Barannikova, J. Mod. Phys. 1, 1 (2010).

6. P. Sofronis, Y. Liang, and N. Aravas, J. Mech. A. Solids 20, 857 (2001).

7. V. P. Ramunni, T. De Paiva Coelho, and P. E. V. de Miranda, Mater. Sci. Eng. A 435-436, 504 (2006).

8. Y. Yagodzinskyy, O. Todoshchenko, S. Papula, and H. Hänninen, Steel Res. Int. 82, 20 (2011).

9. L. B. Zuev, S. A. Barannikova, M. V. Nadezhkin, and V. A. Mel'nichuk, Techn. Phys. Lett. 37, 793 (2011).

10. M. M. Krishtal, A. A. Karavanova, A. A. Jeremic, and I. S. Yasnikov, Acad. Sci. Rep. 425, 754 (2009).

11. S. A. Barannikova, A. G. Lunev, M. V. Nadezhkin, and L. B. Zuev, Adv. Mater. Res. 880, 42 (2014). 